\title{
Peningkatan Kemampuan Komunikasi Dalam Menggunakan Model POE2WE
}

\author{
Dela Nurmayanti ${ }^{1 *}$, Nana ${ }^{2}$ \\ ${ }^{1}$ Mahasiswa Pendidikan Fisika FKIP Universitas Siliwangi \\ ${ }^{2}$ Dosea Pendidikan Fisika FKIP Universitas Siliwangi \\ Jl. Siliwangi No 24 Tasikmalaya Jawa Barat Indonesia 46115 \\ *E-Mail: delanurmayanti14@gmail.com
}

\begin{abstract}
ABSTRAK : Tujuan penulisan ini untuk mendeskripsikan penerapan model POE2WE sebagai upaya melatih kemampuan komunikasi. Penulisan ini di latar belakang oleh masih kurangnya kemampuan menerapkan penguasaan kempuan komunikasi untuk dapat menyelesaikan masalah yang di hadapi. Untuk itu perlu adanya model pembelajaran yang reelevan agar dapat mempersiapkan generasi saat ini untuk siap menghadapi saat nanti, yaitu dengan menerapkan model POE2WE sebagai proses pembelajaran yang menekankan pada keaktifan dari peserta didik dalam melakukan pembelajaran. Metode yang di gunakan dalam penulisan ini yaitu dengan studi kepustakaan dengan mengkaji beberapa literatur untuk di analisis dan di buat kesimpulan. Hasil penulisan ini menunjukan bahwa penerapan pembelajaran melalui model POE2WE dapat melatih kempuan komunikasi. Hal ini di karenakan model POE2WE merupakan pembelajaran yang berpusat pada siswa sehingga siswa tidak diberi informasi melainkan dipancing agar ikut serta mencari informasi kemampuan komunikasi dengan bekal dan pengetahuan yang telah dimiliki.
\end{abstract}

Kata kunci : Pembelajaran, Model POE2WE, Kemampuan Komunikasi

\section{PENDAHULUAN}

Komunikasi atau communication berasal dari kata latin communis yang be-rarti sama, communico, communication, atau communicare yang berbarti membuat sama (to make common). Menurut Dar-modjo (dalam Nana, 2019), Keterampilan mengkomu-nikasikan adalah ketrampilan untuk menyampaikan apa yang ada dalam pikiran dan perasaan kepada orang lain, baik secara lisan maupun secara tertulis. Keterampilan komunikasi lisan dapat dikembangkan secara dini pada anak me-lalui 
berbagai cara. Salah satu cara yang efektif adalah menberi kesempatan kepa-da mereka untuk bekerja dalam kelompok, diskusi kelompok dan menyampaikan hasil, diskusinya kepada kelas. Teman sebaya sebagai mitra yang sangat efektif untuk mengembangkan keterampilan komunikasi verbal karena selama proses berlangsung boleh dikatakan tidak ada hambatan psikologis. Keterampilan mengkomunikasi tertulis dapat berbentuk tulisan, grafik maupun gambar-gambar.

\section{METODE PENELITIAN}

Penelitian ini menggunakan metode literasi (studi pustaka) dengan cara mengkaji berbagai sumber, dan berkaitan dengan penerapan model POE2WE (,Nana, N., \& Pramono, H, Nana. (2014), Nana. (2016), Nana, Sajidan, Akhyar, M., \& Rochsatiningsih, D. (2014).

\section{HASIL DAN PEMBAHASAN}

\subsection{Model POE2WE}

Model pembelajaran Prediction, Observation, Explanation, Elaboration, Write dan Evaluation (POE2WE) dikembangkan dari model pembelajaran POEW dan model pembelajaran Fisika dengan Pendekatan Konstruktivistik. Pengembangan ini dilakukan untuk sebagai penyempurnaan kedua model sebelumnya. Model POE2WE merupakan model pembelajaran yang dikembangkan untuk mengetahui pemahaman peserta didik mengenai suatu konsep dengan pendekatan konstruktivistik. Model ini membangun pengetahuan dengan urutan proses yaitu meramalkan atau memprediksi solusi dari permasalahan, melakukan eksperimen untuk membuktikan prediksi, kemudian menjelaskan hasil eksperimen yang diperoleh secara lisan maupun tertulis, membuat contoh penerapan dalam kehidupan seharihari, menuliskan hasil diskusi dan memuat evaluasi tentang pemahaman peserta didik baik secara lisan maupun tertulis (Nana et al., 2014). Model pembelajaran POE2WE dapat menjadikan peserta didik sebagai subjek di dalam pembelajaran. peserta didik secara aktif menemukan suatu konsep melalui pengamatan atau eksperimen secara langsung, bukan dari menghafal buku materi maupun penjelasan dari guru. Model ini memungkinkan peserta didik aktif dalam proses pembelajaran, memberikan kesempatan kepada peserta didik untuk mengkonstrukssi pengetahuannya mengkomunikasikan pemikirannya dan menuliskan hasil diskusinya sehingga peserta didik lebih menguasai dan memahami konsep yang 
akan berdampak pada peningkatan prestasi belajar peserta didik Model ini memberikan kesempatan kepada peserta didik untuk melakukan konstruksi pengetahuan yang dimilikinya, melakukan pengamatan terhadap fenomena serta mengkomunikasikan gagasan yang dia perolah dari proses diskusi sehingga peserta didik akan lebih mudah menguasai konsep yang diajarkan (Nana, 2014, 2016; Nana etal., 2014; Permatasari, 2011; Rahayu et al., 2013; Samosir, 2010). Penggabungan tahapan-tahapan pembelajaran model POEW dan model pembelajaran Fisika dengan Pendekatan Konstruktivistik maka dapat di susun langkah-langkah pembelajaran model POE2WE secara terinci sebagai berikut:

\section{a) Prediction}

Tahap prediction yaitu peserta didik membuat prediksi atau dugaan awal terhadap suatu permasalahan. Permasalahan yang ditemukan berasal dari pertanyaan dan gambar tentang materi yang disampaikan oleh guru yang ada di Lembar Kerja peserta didik (LKS)/buku peserta didik sebelum peserta didik membuat prediksi. Pembuatan prediksi jawaban tahap Prediction pada model POEW identik dengan fase Engagenent pada pendekatan konstruktivistik. Guru mengajukan pertanyaan yang dapat mendorong peserta didik untuk dapat membuat prediksi atau jawaban sementara dari suatu permasalahan.

\section{b) Observation}

Tahap Observation yaitu untuk membuktikan prediksi yang telah di buat oleh pesera didik. Peserta didik diajak melakukan eksperimen berkaitan dengan masalah atau persoalan yang di temukan. Selanjutnya peserta didik mengamati apa yang terjadi, kemudian peserta didik menguji kebenaran dari dugaan sementara yang telah dibuat. Tahap Observation pada model POEW identik dengan fase Exploration pada pendekatan konstruktivistik.

\section{c) Explanation}

Tahap Explanation atau menjelaskan yaitu peserta didik memberikan penjelasan terhadap hasil eksperimen yang telah dilakukan. Penjelasan dari peserta didik dilakukan melalui diskusi dengan anggota kelompok kemudian tiap kelompok mempresentasikan hasil diskusinya di depan kelas. Jika prediksi yang di buat peserta didik ternyata terjadi di dalam eksperimen, maka guru membimbing peserta didik merangkum dan memberi penjelasan untuk menguatkan hasil eksperimen yang dilakukan. Namun jika prediksi peserta didik tidak terjadi dalam eksperimen, maka guru membantu peserta didik mencari penjelasan mengapa prediksi atau dugaannya 
tidak benar. Tahap explanation identik dengan fase explanation pada pendekatan konstuktivistik.

\section{d) Elaboration}

Tahap elaboration yaitu peserta didik membuat contoh atau menerapkan konsep dalam kehidupan sehari-hari. Tahap elaboration di ambil dari pendekatan konstruktivistik. Tahap ini guru medorong peserta didik untuk menerapkan konsep baru dalam situasi baru sehingga peserta didik lebih memahami konsep yang di ajarkan guru. Tahap ini pengembangan dari pendekatan konstruktivistik.

e) Write

Tahap write atau menulis yaitu melakukan komunikasi secara tertulis,merefleksikan pengetahuan dan gagasan yang dimiliki peserta didik Menurut Masingilia dan Wisniowska (1996) dalam (Yamin \& Ansari, 2012) menulis dapat membantu peserta didik untuk mengekspresikan pengetahuan dan gagasan mereka. peserta didik menuliskan hasil diskusi dan menjawab pertanyaan yang ada pada LKS. Selain itu pada tahap write ini, peserta didik membuat kesimpulan dan laporan dari hasil eksperimen. Tahap ini merupakan pengembangan dari model TTW.

\section{f) Evaluation}

Tahap Evaluation yaitu evaluasi terhadap pengetahuan, keterampilan dan perubahan proses berfikir peserta didik. Pada tahap ini peserta didik di evaluasi tentang materi gerak lurus berupa lisan maupun tulisan. Tahap ini merupakan pengembangan dari pendekatan konstruktivistik. Penggabungan tahap-tahap model POEW dan pendekatan konstruktivistik dapat di lihat pada Tabel 1 dan 2 .

Tabel 1. Sintaks Pengembangan model POE2WE

\begin{tabular}{|l|l|l|}
\hline $\begin{array}{l}\text { No. Sintaks POEW } \\
\text { (Samosir, 2010) }\end{array}$ & $\begin{array}{l}\text { Sintaks model } \\
\text { Pembelajaran } \\
\text { dengan Pendekatan } \\
\text { Konstruktivistik (Duffy } \\
\text { \& } \\
\text { Jonassen, 1992) }\end{array}$ & $\begin{array}{l}\text { Model POE2WE } \\
\text { (Nana et al., 2014) }\end{array}$ \\
\hline $\begin{array}{l}\text { 1. (Prediction) membuat } \\
\text { prediksi, membuat } \\
\text { dugaan }\end{array}$ & $\begin{array}{l}\text { Engagement) } \\
\text { pendahuluan } \\
\text { membuat pertanyaan }\end{array}$ & $\begin{array}{l}\text { (Prediction) } \\
\text { pembuat dugaan atau } \\
\text { prediksi. }\end{array}$ \\
\hline
\end{tabular}




\begin{tabular}{|c|c|c|}
\hline & $\begin{array}{l}\text { menggali pengetahuan } \\
\text { awalpeserta didik. }\end{array}$ & $\begin{array}{l}\text { Tahap Engagement identik } \\
\text { dengan Predict pada } \\
\text { POEW }\end{array}$ \\
\hline $\begin{array}{l}\text { 2. (Observation }) \\
\text { Melakukan penelitian, } \\
\text { pengamatan }\end{array}$ & $\begin{array}{l}\text { (Exploration) menguji } \\
\text { prediksi ,melakukan dan } \\
\text { mencatat hasil } \\
\text { pengamatan. }\end{array}$ & $\begin{array}{l}\text { (Observation) } \\
\text { Melakukan } \\
\text { observasi/pengamatan } \\
\text { Tahap Exploration identik } \\
\text { dengan tahap observation } \\
\text { pada } \\
\text { POEW. }\end{array}$ \\
\hline $\begin{array}{l}\text { 3. (Explanation) } \\
\text { Yaitu memberi } \\
\text { penjelasan }\end{array}$ & $\begin{array}{l}\text { (Explation) menjelaskan } \\
\text { konsep dengan kalimat } \\
\text { mereka sendiri }\end{array}$ & $\begin{array}{l}\text { (Explanation) } \\
\text { Menjelaskan Pada tahap } \\
\text { explanation identik dengan } \\
\text { explation pada pendekatan } \\
\text { konstruktivistik }\end{array}$ \\
\hline $\begin{array}{l}\text { 4. (Write) } \\
\text { Membuat kesimpulan }\end{array}$ & $\begin{array}{l}\text { (Elaboration) } \\
\text { Aplikasi konsep dalam } \\
\text { kehidupan sehari-hari. }\end{array}$ & $\begin{array}{l}\text { (Elaboration) } \\
\text { Aplikasi konsep dalam } \\
\text { kehidupan sehari-hari } \\
\text { merupakan pengembangan } \\
\text { dari pendekatan } \\
\text { Konstruktivistik }\end{array}$ \\
\hline 5. & $\begin{array}{l}\text { Evaluasi terhadap } \\
\text { pengetahuan, keterampilan } \\
\text { dan perubahan proses } \\
\text { berfikir peserta didik. }\end{array}$ & $\begin{array}{l}\text { (Write }) \\
\text { Menuliskan hasil diskusi } \\
\text { sebagai kesimpulan. } \\
\text { Merupakan pengembangan } \\
\text { dari model POEW }\end{array}$ \\
\hline 6. & & $\begin{array}{l}\text { (Evaluation) } \\
\text { Evaluasi terhadap } \\
\text { efektifitas } \\
\text { fase-fase sebelumnya. }\end{array}$ \\
\hline
\end{tabular}




\begin{tabular}{|l|l|}
\hline & $\begin{array}{l}\text { Merupakan pengembangan } \\
\text { dari pendekatan } \\
\text { Konstruktivistik }\end{array}$ \\
\hline
\end{tabular}

Tabel 2. Kegiatan pembelajaran Model Pembelajaran Model POE2WE

\begin{tabular}{|c|c|c|}
\hline Fase- fase & Guru Kegiatan & Peserta Didik \\
\hline Prediction & $\begin{array}{l}\text { Prediction } \\
\text { Menyampaikan tujuan } \\
\text { pembelajaran. } \\
\text { - Mengajukan pertanyaan } \\
\text { kepada } \\
\text { siswa } \\
\text { - } \quad \text { Menginventarisir } \\
\text { prediksi dan } \\
\text { alasan yang di kemukakan } \\
\text { peserta } \\
\text { didik. }\end{array}$ & $\begin{array}{l}\text { Memperhatikan penjelasan } \\
\text { dari guru. } \\
\text { - Memprediksi jawaban } \\
\text { pertanyaan dari guru } \\
\text { - Mendiskusikan hasil } \\
\text { prediksinya }\end{array}$ \\
\hline Observation & $\begin{array}{l}\text { - Mendorong peserta didik } \\
\text { untuk } \\
\text { bekerja secara kelompok } \\
\text { - Membagikan LKS } \\
\text { - Mengawasi kegiatan } \\
\text { percobaan } \\
\text { yangdilakukan oleh } \\
\text { peserta didik }\end{array}$ & $\begin{array}{l}\text { - Membentuk kelompok } \\
\text { - Melakukan percobaan } \\
\text { - Mengumpulkan data } \\
\text { hasil } \\
\text { percobaan } \\
\text { - Melakukan diskusi } \\
\text { kelompok } \\
\text { - Menyimpulkan hasil } \\
\text { percobaan }\end{array}$ \\
\hline Explanation & $\begin{array}{l}\text { - Mendorong peserta didik } \\
\text { untuk } \\
\text { menjelaskan hasil } \\
\text { percobaan. } \\
\text { - Meminta peserta didik } \\
\text { pempresentasikan hasil }\end{array}$ & $\begin{array}{l}\text { - Mengemukakan } \\
\text { pendapatnya } \\
\text { tentang hasil percobaan } \\
\text { - Mengemukakan } \\
\text { pendapatnya } \\
\text { tentang gagasan baru }\end{array}$ \\
\hline
\end{tabular}




\begin{tabular}{|c|c|c|}
\hline & $\begin{array}{l}\text { percobaannya } \\
\text { - Mengklarifikasikan hasil } \\
\text { Percobaannya } \\
\text { - Menjelaskan } \\
\text { konsep/definisi baru }\end{array}$ & $\begin{array}{l}\text { berdasarkan hasil } \\
\text { percobaan. } \\
\text { - Menanggapi presentasi } \\
\text { dari } \\
\text { kelompok lain. } \\
\text { - Konsep baru dari guru } \\
\text { dapat } \\
\text { di terima }\end{array}$ \\
\hline Elaboration & $\begin{array}{l}\text { - Memberi permasalahan } \\
\text { berkaitan } \\
\text { dengan penerapan konsep. } \\
\text { - Mendorong peserta didik } \\
\text { untuk } \\
\text { menerapkan konsep baru } \\
\text { dalam } \\
\text { situasi baru. }\end{array}$ & $\begin{array}{l}\text { - Menerapkan konsep baru } \\
\text { dalam situasi baru atau } \\
\text { kehidupan sehari-hari. }\end{array}$ \\
\hline Write & $\begin{array}{l}\text { - Memberi kesempatan } \\
\text { kepada } \\
\text { peserta didik untuk } \\
\text { mencatat hasil } \\
\text { diskusi serta kesimpulan. }\end{array}$ & $\begin{array}{l}\text { - Mencatat hasil penjelasan } \\
\text { dan kesimpulan dari guru } \\
\text { dan } \\
\text { diskusi kelompok }\end{array}$ \\
\hline Evaluation & $\begin{array}{l}\text { Evaluation - Mengajukan } \\
\text { pertanyaan untuk } \\
\text { penilaian proses } \\
\text { - Menilai pengetahuan } \\
\text { peserta didik } \\
\text { - Memberikan balikan } \\
\text { terhadap } \\
\text { jawaban peserta didik }\end{array}$ & $\begin{array}{l}\text { - Mencatat hasil penjelasan } \\
\text { dan kesimpulan dari guru } \\
\text { dan diskusi kelompok } \\
\text { - Menjawab pertanyaan } \\
\text { berdasarkan data } \\
\text { - Mendemonstrasikan } \\
\text { kemampuan dalam } \\
\text { penguasaan konsep }\end{array}$ \\
\hline
\end{tabular}


Komunikasi menyarankan bahwa suatu pikiran, suatu makna, atau suatu pesan dianut secara sama. Menurut Shannon dan Weaver (Sulistyo-Basuki, 1996: 18) (dalam Nana, 2019), komponen komunikasi terdiri atas sumber (source), pemancar (transmit-ter), saluran (channel), penerima (receiver) dan tujuan (destination). $\mathrm{M}$ odel komu-nikasi tersebut dikenal sebagaL model transmisi yang banyak diadopsi dalam bi-dang bidang telekomunikasi.

Namun demikian Littejohn (2002) melihat proses komunikasi berdasarkan perspektif yang non transmisi/Littejohn menyebut: "communication involves understanding how people behave in creating, exchanging, and interpretating message. Consequently, communication inquiry combines both scientific and humanistic methods". Konsep pendekatan scientific scholarship dalam komunikasi menurut Littlejohn selalu diasosiasikan dengan ob-jektifitas. Proses komunikasi texjadi anta-ra sesama manusia melalui berbagai me-dia seperti suara, sinyal, surat, telepon, televisi, buku, media cetak.

Komunikasi terbagi menjadi komunikasi verbal dan nonverbal. Komu-nikasi verbal yaitu komunikasi melalui bahasa. Sedangkan komunikasi nonverbal melalui isyarat (gestur), gerak-gerik, sua-tu barang atau hal yang lainnya. Dalam komunikasi ilmiah yang digunakan tentu komunikasi verbal. Komunikasi verbal yaitu komunikasi yang mengunakan ba-hasa sebagai hasil transformasi dari objek yang bersifat faktual menjadi simbol yang abstrak. Hal inilah yang kemudian me-nyebabkan manusia mampu memikirkan sesuatu.

Motley dalam Prasetyo (2014), (dalam Nana, 2019) ber-pendapat bahwa komunikasi adalah transmisi informasi, baik bersifat verbal maupun non-verbal. Berbagai perspektif definisi proses komunikasi inilah yang akan mengantarkan pada pendekatan komunikasi ilmiah yang lebih banyak ter-jadi dalam dimensi riset, inquiry, dan in-vensi dari para ilmuwan (researcher).

Sebagai mahluk sosial manusia ha-rus dapat berkomunikasi dengan manusia lainnya. Dalam blognya dicky umbara (2007) mengatakan bahwa:

Komunikasi adalah suatu proses penyam-paian pesan (ide, gagasan) dari satu pihak kepada pihak lain agar terjadi saling rnempengaruhi diantara keduanya. Pada umumnya, komunikasi dilakukan dengan menggunakan kata-ltata (lisan) yang dapat dimengetti oleh kedua belah pihak. Apabila tidak ada bahasaverbal yang dapat 
dimengerti oleh keduanya, komu-nikasi masih dapat dilakukan dengan menggunakan gerak-gerik badan, menun-jukkan sikap tertentu, misalnya tersenyum, menggelengkan kepala, mengangkat bahu. Cara seperti ini disebut komunikasi dengan bahasa nonverbal atau bahasa isyarat.

Sehingga dapat disimpulkan bahwa komunikasi merupakan kegiatan penyampaian ide gagasan dari seseorang kepada orang lain baik secara verbal atau nonverbal. Lougee dalam (Siswadi, 2009) men-jelaskan proses komunikasi ilmiah dapat mempelajari berbagai bidang ilmu (fisika, biologi, sosial, psikologi, humaniora, teknologi) memanfaatkan dan menyebar-kan informasi melalui saluran formal dan informal. Kajian komunikasi ilmiah men-cakup perkembangan ilmu pengetahuan, hubungan antara peneliti dalam berbagai disiplin ilmu, pemanfaatan dan kebutuhan informasi dari kelompok pemustaka, serta metode komunikasi baik formal maupun informal. Dengan demikian komunikasi ilmiah (scholarly or scientific communication) adalah komunikasi yang umumnya berkaitan dengan kegiatan-kegiatan penelitian atau penyelidikan, khususnya di lingkungan akademik. Pada pembelaja-ran sekolah menengah dapat diwujudkan dengan adanya percobaan, penyelesaian sebuah masalah, pembuatan karya ilmiah dan lain sebagainya.

Komunikasi ilmiah menuntut ke-mampuan berbahasa dengan jelas. Hal ini berarti kata-kata yang digunakan harus diungkapkan secara eksplisit untuk mencegah kasalahpahaman makna. Oleh karena itulah dalam komunikasi ilmiah sering ditpmukan definisi dari kata-kata yang dipergunakan. Hal ini dilakukan agar komunikan tidak memberi arti atau definisi yang berbeda dari makna yang dimaksudkan komunikator. Jika hal ter-sebut teijadi, maka akan menghasilkan proses berpikir yang berbeda pula. Dalam makalahnya Choirul Hadi menjelaskan bahwa hakikat bahasa komunikasi ilmiah sekurang-kurangnya didukung oleh tiga variabel:

(1) kemampuan berpikk kritis (critical thinking), (2) penguasaan bahasa, dan (3) pengetahuan umum yang luas. Pen-guasaan pengetahuan umum tampaknya lebih mudah dikejar. Tinggal membaca buku, jurnal, majalah, surat kabar, dan akses melalui internet.

Sebaliknya, kemampuan berpikir kritis, berdebat, beradu argumentasi dalam bahasa komunikasi ilmiah tampaknya agak sulit ditanamkan kepada kalangan masyarakat akademik. Masa-lahnya, paling tidak ada tiga hambatan cultural yang masih menghantui kalangan masyarakat akademik kita. Ketiga ham-batan itu harus dirombak dan segera dil-akukan transforaiasi, yaitu: (1) warisan cultural-edukasional, 
(2) kompetensi dan performansi linguistik, dan (3) masalah psikologis. Untuk mernerangi ketiga ham-batan tersebut perlu dilakukan \%upaya pembenahan pendidikan yang serius dan membutuhkan waktu yang panjang dan lama. Pembenahan pendidikan bukan saja secara formal pada jenjang pendidikan da-sar sampai universitas (perguruan tinggi), tetapi harus dimulai sejak dini, yakni pendidikan dalam keluarga (informal), dan pendidikan dalam masyarakat (nonformal). (2013) Karso $d k k$ (1993) mengungkapkan bahwa indikator komunikasi ilmiah meli-puti: (a) menyusun dan menyampaikan laporan secara sistematik dan jelas, (b) menjelaskan hasil percobaan, (c) mendiskusikan hasil percobaan, (d) mengklasifikasikan data dan menyusun data serta (e) menggambarkan data dalam grafik, tabel, atau diagram. Sutardi (2008) mengungkapkan kemampuan siswa berkomunikasi ilmiah meliputi kemampuan membuat tabel perhitungan, membuat grafik, dan mengintepretasikan grafik. Kemampuan berkomunikasi ilmiah dapat diukur dengan pengamatan terhadap siswa dalam praktikum. Kemampuan menjelaskan hasil pengamatan merupakan kemampnan siswa dalam memaparkan temuan atau data yang mereka alami saat melakukan percobaan. Data hasil praktikum tidak hanya dikumpulkan dan diolah, tetapi ju-ga perlu disajikan dalam bentuk yang mu-dah dibaca dan dimengerti oleh pengambil keputusan. Penyajian data ini bisa dalam bentuk tabel dan grafik, oleh karena itu lebih dengan cepat ditangkap dan di-mengerti. Tabel adalah kumpulan angka-angka yang disusun menurut kategori. Grafik adalah gambaran yang menun-jukan secara visual data berupa angka. Hasil pengamatan yang akan diamati da-lam penelitian ini adalah sajian data dengan tabel ataupun dengan grafik dan menyangkup semua hasil pengamatan. Hasil percobaan ini dijelaskan di dalam laporan praktikum siswa (Risty, 2013).

Diskusi sebagai metode pembelaja-ran adalah proses pelibatan dua orang peserta atau lebih untuk berinteraksi saling bertukar pendapat, dan atau saling mempertahankan pendapat dalam pemecahan masalah sehingga didapatkan kesepaka-tan diantara mereka. Pembelajaran yang menggunakan metode diskusi merupakan pembelajaran yang bersifat interaktif (Gagne \& Briggs. 1979). Manakala salah satu diantara siswa berbicara, maka siswa»siswa lain yang menjadi bagian dari kelompoknya aktif mendengarkan. Siapa yang berbicara terlebih dahulu dan begitu pula yang menanggapi, tidak harus diatur terlebih dahulu. Dalam berdiskusi, seringkali siswa saling menanggapi jawaban te-mannya atau berkomentar terhadap jawaban yang diajukan siswa lain. Siswa juga kadang-kadang mengundang anggota ke- 
lompok lain untuk bicara, sebagai nara-sumber. Dalam penentuan pimpinan diskusi, anggota kelompok dapat menetapkan pemimpin diskusi mereka sendiri. Sehingga melalui metode diskusi, keaktifan siswa sangat tinggi (McKeachie dan Kulik, 1984).

\section{KESIMPULAN}

Dari berbagai pembahasan yang telah dijaarkan dapat ditarik kesimpulan dan dimaknai bahwa pembelajaran model POE2WE dapat melatih kemampuan komunikasi dalam pembelajaran fisika di SMA. Hal ini karena model POE2WE merupakan pembelajaran yang berpusat pada siswa sehingga siswa tidak hanya diberikan informasi melainkan dipancing agar ikut serta mencari informasi dengan bekal pengetahuan yang dimiki.

\section{UCAPAN TERIMA KASIH}

Terima kasih kepada Drs. Nana., S.Pd., M.Pd., selaku dosen pengampu mata kuliah Fisika Sekolah II dan semua pihak yang telah membantu demi kesempurnaan artikel ini menjadi lebih baik.

\section{REFERENSI}

Nana. (2014). Pengembangan model POE2WE dalam pembelajaran Fisika SMA. Universitas Sebelas Maret

Nana, Sajidan, Akhyar, M., \& Rochsatiningsih, D. (2014). The development of Predict, Observe, Explain, Elaborate, Write, and Evaluate (POE2WE) Learning Model in Physics Learning at Senior Secondary School. Journal of Education and Practice,5(19), 56-65.

Nana. (2016). Pengembangan Model Pembelajaran Prediction, Observation, Explanation, Elaboration, Write, and Evaluating (POE2WE) dalam Pembelajaran Fisika SMA. Universitas Sebelas Maret.

Nana, N., \& Pramono, H. (2019). Upaya Peningkatan Kemampuan Kognitif dan Komunikasi Ilmiah Siswa Kelas X MIA 1 SMA Negeri 1 Ciamis Menggunakan Model Pembelajaran Inquiri. DIFRACTION, 1 (1) 